\title{
FENOMEN „SITULI"? - ZNACZENIE NACZYŃ GLINIANYCH OKREŚLANYCH MIANEM ,SITUL" W OBRZĄDKU POGRZEBOWYM LUDNOŚCI KULTURY WIELBARSKIEJ W WIELKOPOLSCE
}

\author{
THE PHENOMENON OF "SITULAS"? - THE ROLE \\ OF POTTERY VESSELS DETERMINED AS “SITULAS” \\ IN THE WIELBARK CULTURE BURIAL RITE \\ IN WIELKOPOLSKA (GREATER POLAND, POLAND)
}

\author{
Daniel Żychliński \\ APB THOR Sp. z o.o. \\ Al. Reymonta 21, 62-200 Gniezno, Poland \\ daniel.zychlinski@gmail.com
}

\begin{abstract}
The aim of this article is to present issues concerning the presence of so called situlas (pottery vessels, no bronze) in Wielbark culture inventories from Wielkopolska. These vessels are very rare within cemeteries and settlements as well. And until now the criteria of such spatial distribution have remained unknown. In this paper so called situlas from Wielkopolska will be characterised, particularly in the context of their deposition in individual graves and within the necropolises, as well as within settlements. Further parts of this article deal with research problems connected with the role and meaning of so called situlas in Wielbark culture burial rite in Wielkopolska, in particular in the light of anthropological analysis results. The paper also presents the hypothesis explaining sparsity of so called situlas occurrence and very specific localisation of these vessels in the area of Wielkopolska. At the end of the article research demands and questions will be presented. They will enable and give direction for further discussion on the compelling issue of phenomenon of so called situlas of full spatial and chronological aspects of their occurrence.
\end{abstract}

KEY WORDS: Wielbark culture, "situlas”, burial rite, cemeteries, settlements.

Pytanie postawione w tytule niniejszego przyczynku jest o tyle stosowne, o ile „situle” rzeczywiście spotykane są na wielkopolskich terytoriach ludności wielbarskiej niezwykle rzadko, a co za tym idzie: każde ich pojawienie się stanowi znaczący ewenement. 
Według definicji Ryszarda Wołągiewicza „situle”, czyli typ V typologii ceramiki ludności kultury wielbarskiej,

[...] to naczynia o wysmukłej dolnej części korpusu z wysoko umieszczoną największą wydętością brzuśca i rozchylonym wylewem [...]. Situle należą do tzw. ceramiki stołowej, są starannie wykonane. Powierzchnia ich jest gładka, często wyświecana, barwy czarnej, szarej lub brunatnej, a chropowacenie brzuśca jest drobnoziarniste i służy wyłącznie celom dekoracyjnym [...].

Należy także dodać, że nieodzowną cechą tego typu naczyń jest bardzo bogate i zróżnicowane zdobnictwo. Datowane są pewnie w przedziale faz $\mathrm{B}_{1}$ wczesnego po $\mathrm{B}_{2} / \mathrm{C}_{1}$ późnego okresu wpływów rzymskich (Wołągiewicz 1993, s. 13-14, 26).

W tym miejscu należy jednak zwrócić uwagę na nazwę ,situla” użytą tu w cudzysłowie. Definicja, którą podaje Stownik języka polskiego PWN, brzmi: „wiadro z brązu z okresu halsztackiego i lateńskiego" (http://sjp.pwn.pl/szukaj/situla.html), a więc podkreśla fakt wykonania takiego pojemnika $\mathrm{z}$ brązu. Natomiast $\mathrm{w}$ terminologii angielskiej brzmi ona nieco inaczej: „a bucket-shaped container, usually of metal or pottery and often richly decorated [...]" (http://www.thefreedictionary. com/Situla), a więc dopuszcza równoprawnie możliwość istnienia „situli” jako pojemnika ceramicznego.

I choć nazwa zastosowana przez R. Wołągiewicza (znamienitego przecież badacza kultury wielbarskiej!) dla tego typu naczyń nie jest do końca adekwatna, to jednak jest bardzo silnie zakorzeniona w literaturze przedmiotu i nie ma sensu wprowadzać tu zamętu terminologicznego. Aby jednak odróżnić przedmiot niniejszego artykułu od „klasycznych situl”, zastosowano zabieg polegający na wprowadzeniu cudzysłowu.

W swojej pracy R. Wołągiewicz uwzględnił 99 „,situl”, które pochodziły w znakomitej większości ze stanowisk sepulkralnych (Wołągiewicz 1993, s. 7, lista 5). Obszar występowania tych naczyń zamykał się przede wszystkim w ramach Pomorza Gdańskiego i wschodniej części Pomorza Zachodniego, a także Powiśla, przy śladowej ich obecności na zachodnich rubieżach Mazur, w Północnej Wielkopolsce i na prawobrzeżnym Mazowszu. W ujęciu chronologicznym terytoria te pokrywały się z zasięgiem występowania kultury wielbarskiej $\mathrm{w}$ fazie $\mathrm{B}_{2}$ wczesnego okresu rzymskiego (Wołągiewicz 1993, s. 30, mapa 5).

\section{„SITULE” Z WIELKOPOLSKI}

Na naczynia tego typu natrafiano w Wielkopolsce wyjątkowo rzadko. Do 1993 r., a więc od momentu ukazania się pracy R. Wołągiewicza, znane były zaledwie dwa stanowiska, obydwa o charakterze sepulkralnym, gdzie zarejestrowano „situle”. 
Pierwsze z nich to wysunięta na zachód Wielkopolski nekropola w Brójcach, pow. międzyrzecki, która dostarczyła trzech naczyń omawianego typu - pojedynczego kompletnego, następnego zachowanego jedynie w części przydennej i kolejnego, co do którego taka klasyfikacja budzi zastrzeżenia. Niestety brakuje tu informacji na temat form grobów, w których omawiane naczynia odkryto. Analogicznie brakuje ekspertyz antropologicznych. Wzmianka, że trzecia situla pochodziła z grobu dziecka, nie jest jednak potwierdzona naukowo (Umbreit 1976, s. 47, Abb. 3 ).

Drugie cmentarzysko to położone w środkowej Wielkopolsce Słopanowo, pow. szamotulski, stan. I. Dostarczyło ono następnego, zachowanego jedynie częściowo egzemplarza „situli”. Jego przynależność typologiczna nie budzi jednak wątpliwości, a ponadto zdobiony jest on rozbudowanym systemem swastyk. Naczynie to odkryto w nieokreślonym antropologicznie grobie szkieletowym nr 56, wyposażonym w trzy zapinki i datowanym na koniec II w. n.e. (Przewoźna 1955, s. 122, 130, ryc. $82: 1$ ), a więc na fazę $\mathrm{B}_{2} / \mathrm{C}_{1}$. Niestety brakuje informacji na temat lokalizacji „situli” w obrębie jamy grobu.

W latach następnych naczynia omawianego typu coraz częściej, choć nadal rzadko, zaczęto odkrywać również na innych wielkopolskich stanowiskach wiązanych z osadnictwem ludności wielbarskiej, także o charakterze osadowym.

Sytuacja taka miała miejsce w Kowalewku, pow. obornicki, na stanowisku 3, będącym pozostałością dwufazowej osady - ludności wielbarskiej, a następnie przeworskiej, gdzie natrafiono na dwie ,situle” (Żychliński 1999, s. 191, tab. IV:2), a dwa kolejne pojemniki sklasyfikowano w ten sam sposób jedynie hipotetycznie; z tego też względu nie zostały tu uwzględnione. Na pojedynczym naczyniu elementem motywu była swastyka (Żychliński 1999, tab. IV:2). Znaleziska te pochodziły z fazy B B $_{2}$ (Żychliński 1999, s. 196).

Na siedem następnych okazów (z czego dwa budziły wątpliwości) natrafiono nieopodal, na „sztandarowym” wielkopolskim cmentarzysku ludności kultury wielbarskiej w Kowalewku nr 12 (Skorupka 2001, s. 131, tab. 10:35/1; 15:54/1, 54/2; 39:129/1; 39:130/1). Z grobu nr 33 pochodziła „situla”, którą wykorzystano jako pojemnik na prochy zmarłego - osobnika nieokreślonego. Nie zarejestrowano tam zarysu jamy grobowej. Brakowało także wyposażenia. Obiekt ten był datowany na fazę $\mathrm{B}_{2} / \mathrm{C}_{1}$ (Skorupka 2001, s. 22). W grobie popielnicowym nr 35 analogicznie, jak wyżej, „situla” (jednak nie ma tu całkowitej pewności co do formy) kryła także skremowane szczątki dorosłego osobnika nieokreślonej płci. Również i w tym przypadku nie odnotowano śladów jamy grobowej i nie odkryto wyposażenia. Chronologia tego obiektu zamknęła się w ramach stadiów $B_{2 b}-B_{2} / C_{1}$ (Skorupka 2001, s. 23). Kolejny grób popielnicowy nr 54 - pochowano tu prawdopodobnie dziecko w wieku infans $I$. W tym jednak przypadku zarys jamy grobu był wyraźnie widoczny, lecz również nie znaleziono wyposażenia. Obiekt wydatowano na fazy $\mathrm{B}_{2 \mathrm{~b}}-\mathrm{B}_{2} / \mathrm{C}_{1}$ (Skorupka 2001, s. 27). W zespole grobowym nr 129 wewnątrz ,situli”, zdobionej meandrem, odkryto skremowane szczątki osobnika infans II (?) oraz wyposażenie. 
Jama grobu nie była widoczna, a pochówku dokonano w stadium $\mathrm{B}_{2 \mathrm{~b}}$ (Skorupka 2001, s. 44). Analogiczną sytuację odnotowano w popielnicowym grobie $\mathrm{nr} 130$, gdzie materiał kostny niepodlegający klasyfikacji oraz wyposażenie również znajdowały się wewnątrz „,situli” ornamentowanej meandrem, która została zdeponowana $\mathrm{w}$ jamie o nieczytelnym zarysie. Obiekt wydatowano na fazę $\mathrm{B}_{2} / \mathrm{C}_{1}$ (Skorupka 2001, s. 44). Natomiast w szkieletowym grobie $\mathrm{nr} 235$, w którym pochowano mężczyznę w wieku 20-25 lat, potłuczona i niekompletna „situla” była umieszczona na prawej kości udowej. Obiekt przyporządkowano do stadium $B_{2 b}$ (Skorupka 2001, s. 68). Ostatnie, niepewne naczynie omawianego typu pochodziło z grobu popielnicowego nr 238 (także bez widocznego zarysu jamy), który wkopano w jamę grobu szkieletowego. Według autora opracowania naczynie to zostało zniszczone w trakcie rabunku grobu szkieletowego. Odkrytych tu szczątków kostnych nie można było określić antropologicznie. Grób ten pochodził z fazy $\mathrm{B}_{2 \mathrm{~b}}$ (Skorupka 2001, s. 69). W przypadku tak dokładnie zbadanego cmentarzyska można także rozpatrzyć kwestię rozmieszczenia „situl” w obrębie przestrzeni grzebalnej (Skorupka 2001, s. 166). Niestety nie odnotowano istotnych regularności. Można natomiast stwierdzić, że cztery groby popielnicowe tworzą zgrupowanie w północno-wschodniej części nekropoli. Pojedynczy grób szkieletowy był od nich znacznie oddalony na południe, natomiast pozostałe dwa przypadki ciałopalne zlokalizowane były dalej na zachód - jeden znajdował się w centralnej części cmentarzyska, drugi na zachodniej jego rubieży.

Nieznaną liczbę ,situl”, a z pewnością pojedynczy okaz zdobiony swastyką wplecioną w meander, odkryto na osadzie w Goślinowie, pow. gnieźnieński, stan. 3, gdzie przypisano je do fazy $\mathrm{B}_{2} / \mathrm{C}_{1}$ (Machajewski 2003, s. 232, ryc. 3:4). Jest to drugie stanowisko o charakterze osadowym, gdzie w ogóle odnotowano obecność tych naczyń.

Prawdopodobnie „situlę” ornamentowaną układem swastyk odkryto w trakcie badań osiedla w Siedleczku, pow. wągrowiecki, stan. 4. Funkcjonowanie tej osady zamknięto $\mathrm{w}$ ramach od fazy $\mathrm{B}_{2}$ po początki późnego okresu wpływów rzymskich (Dernoga 2000b, s. 193, 202-203, ryc. 10:12).

Ostatni, jak do tej pory, pewny egzemplarz „situli”, także zdobiony swastykami w różnych wariantach, pozyskano w trakcie ratowniczych badań na stanowiskach 1 i 13 w Wagowie, pow. poznański; stanowiły one rzeczywiście jedną osadę, a pracami wykopaliskowymi objęto znaczny obszar strefy gospodarczej, gdzie bardzo intensywnie prowadzona była obróbka żelaza. Założenie to funkcjonowało między fazami $\mathrm{B}_{2}$ a $\mathrm{B}_{2} / \mathrm{C}_{1}$ (Michałowski, Piasecka, Piasecki, Pogodziński i Żychliński [w druku]).

Na tym można zakończyć przegląd znanych z Wielkopolski „situl” ludności kultury wielbarskiej. Co bardzo interesujące, naczyń tych nie odnotowano w ogóle na innych osadach, nierzadko blisko sąsiadujących z tymi, na których je rejestrowano. „Situle” nie wystąpiły w materiałach ze Stroszek (Gałęzowska 2004, s. 317, 318) oddalonych od Wagowa nieco ponad $10 \mathrm{~km}$. Nie odkryto ich także w Tarnowie Pa- 
łuckim odległym jedynie o $5 \mathrm{~km}$ od osiedla w Siedleczku (Dernoga 2000a, s. 215, 230). Nie zarejestrowano ich także na innych niż wymienione wyżej cmentarzyskach. Przykładowo: brakuje ich w Lutomiu, pow. międzychodzki, jak również w Imielnie, pow. gnieźnieński (Machajewski, Sikorski 1981; Skorupka, Strzyżewski 2006), nieodległych od osad w Wagowie i Modliszewie.

Podsumowując powyższą prezentację można stwierdzić, że „situle” wystąpiły tylko na 7 stanowiskach ludności wielbarskiej w Wielkopolsce. Były to 3 cmentarzyska i 4 osady, na których łącznie odkryto 18 naczyń, w tym 11 pewnych. Na nekropolach znaleziono 11 ,situl”, z czego 7 nie wzbudzało wątpliwości. Natomiast z osiedli pochodzi dalszych 7 egzemplarzy, z których 5 można pewnie sklasyfikować. W 5 przypadkach odkryte naczynia były zdobione układami meandrowymi lub pasowymi zbudowanymi ze swastyk.

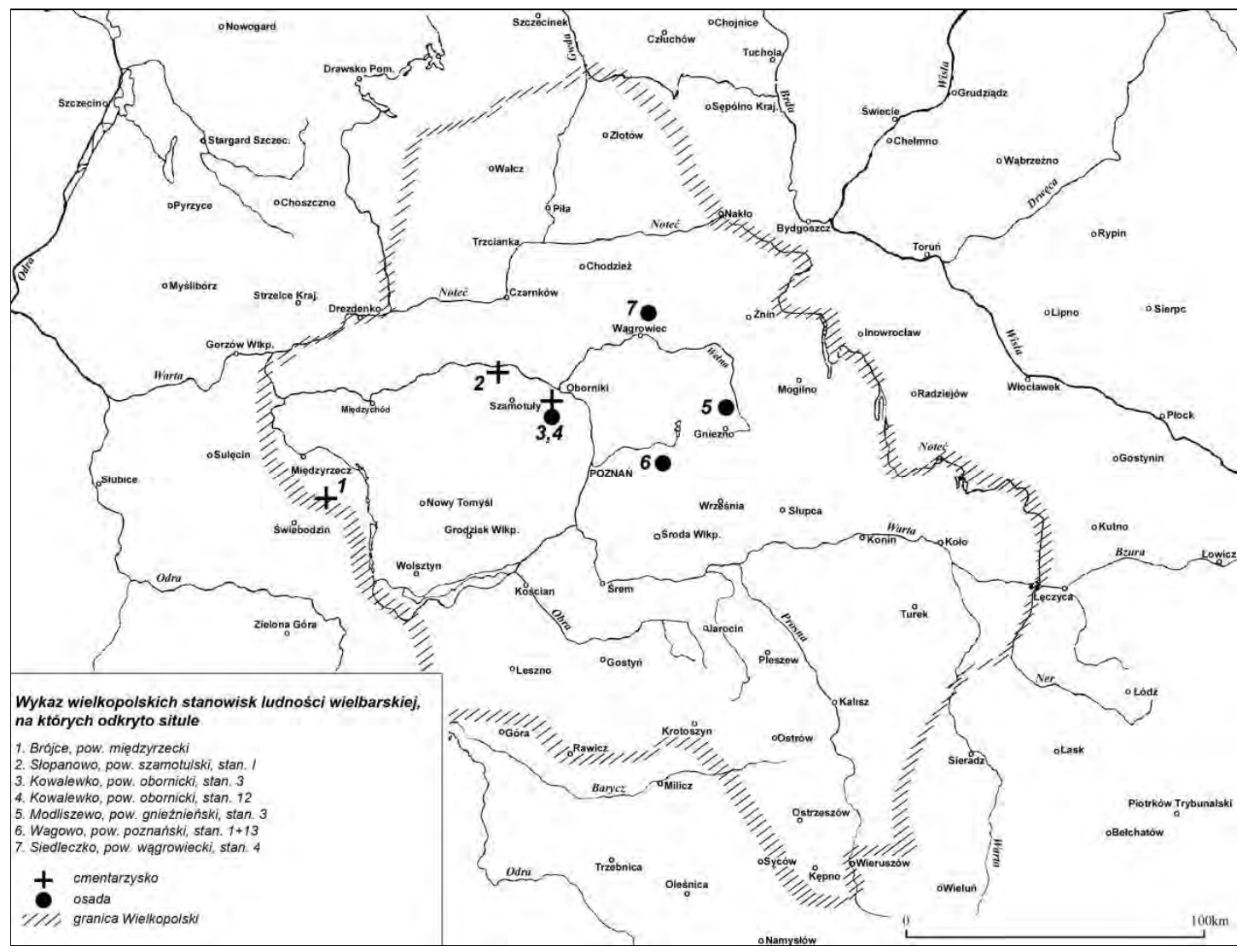

Ryc. 1. Lokalizacja stanowisk ludności kultury wielbarskiej w Wielkopolsce, na których odkryto „situle”

Fig. 1. Location of the Wielbark culture sites with "situlae" in Wielkopolska 
Rozkład przestrzenny tych stanowisk przedstawiono na mapie 1, lecz niestety, poza tym, iż cmentarzyska ,grawitują" w kierunku zachodnim, a osady we wschodnim, brakuje tu jakichkolwiek uchwytnych reguł lokalizacji. Należy jednak podkreślić, że pomiędzy tymi punktami zarejestrowano znaczną liczbę cmentarzysk (por. Żychliński 2014, s. 60, 61, mapa 6 i 7), na których „situle” w ogóle nie występowały.

\section{PROBLEMY BADAWCZE}

Jaka zatem była rola „situl” w obrzędowości pogrzebowej ludności wielbarskiej w Wielkopolsce, skoro odnotowuje się je na trzech tylko cmentarzyskach? Interesującą propozycją byłoby tu stwierdzenie, że tak wyjątkowa forma naczynia była przeznaczana na pochowanie wyjątkowego członka społeczności. Niestety, z przytoczonego powyżej zestawienia wynika, że brakuje elementów wspólnych identyfikowanych wyłącznie z grobami zawierającymi „situle”. Analizy materiału kostnego prezentują znaczne spektrum wiekowe - od małych dzieci po osobniki dorosłe. Groby z omawianymi naczyniami nie miały specjalnych konstrukcji. Nie ma w nich też charakterystycznych elementów wyposażenia. Jak się wydaje, jedyną cechą wspólną, i tylko na cmentarzysku w Kowalewku, był nieczytelny zarys jamy grobów popielnicowych. Jednak ta właściwość informuje jedynie o szybkim i jednorazowym akcie depozycji bez resztek stosu ciałopalnego. Nie sposób zatem potwierdzić podniesionego tu założenia, że „situla” jako popielnica poprzez swoją rzadkość była zarezerwowana dla jednostek wybitnych.

Kolejną kwestią jest częstość występowania omawianych tu naczyń na cmentarzyskach i osadach. Częściowo zagadnienie to wyjaśnia sytuacja stanowisk w Kowalewku - osady oraz nekropoli oddalonych od siebie o ok. $1 \mathrm{~km}$ (Skorupka 2001, s. 261), które tworzyły zapewne wspólną strukturę. Wydaje się zasadne, by założyć, że naczynia te miały przeznaczenie stricte funeralne, a więc docelowo trafiały na cmentarzysko. Dlatego też okazy uszkodzone, zniszczone pozostawały na osiedlach, gdzie je wytworzono. Bardzo interesująco przedstawia się sytuacja grobu $\mathrm{nr} 235$ ze stanowiska nr 12 w Kowalewku, gdyż tu „situla” w stanie niekompletnym została zdeponowana intencjonalnie $\mathrm{w}$ grobie szkieletowym. Czyżby zatem była to forma pars pro toto - tak powszechna $\mathrm{w}$ obrzędowości ludności przeworskiej w Wielkopolsce (Żychliński 2014, s. 110, 140)?

Nekropola w Kowalewku jako jedyna dostarczyła możliwości analizy przestrzennej znalezisk „situl” w obrębie przestrzeni grzebalnej. Badacze tych struktur wykazali, że odległość pomiędzy pochówkami przekłada się na „odległość” pomiędzy jednostkami w żywym społeczeństwie. Czynnik ten ma zatem bardzo istotne zastosowanie w rozwoju przestrzennym i strukturze cmentarzysk (Ciesielski 2011; Woźny 2000, s. 93-94). Przyjmując takie założenie, można uznać zgrupowanie czterech grobów popielnicowych z Kowalewka za centrum układu określonej grupy, a groby położone dalej - za jednostki, które odeszły od jego środka. 
W niniejszych rozważaniach istotna wydaje się również kwestia bogatej ornamentyki znajdującej się na „situlach”, co podkreślał już R. Wołągiewicz (1993, s. 14), a zwłaszcza obecności meandrów i powiązanych z nimi lub samodzielnych swastyk. Badacze zagadnienia są zgodni co do interpretacji ostatnich z wymienionych jako symbolu solarnego, który był wykorzystywany w różnorodnych odmianach na znacznych terytoriach i w szerokim spektrum czasowym (Alfawicka 1970, s. 39; Bugaj 1999, s. 183-187; Biedermann 2001, s. 353; Szamałek 2009, s. 97).

\section{HIPOTEZY}

Na zakończenie tych rozważań należy stwierdzić, że choć ujawnione fakty archeologiczne nie pozwalają na jednoznaczną interpretację ,situl” jako wyjątkowego elementu grobu, to jednak pośrednio wskazują na inność pochowanego w nim członka społeczności. Być może nie należy tego zagadnienia rozpatrywać w ramach „wybitnej jednostki”, lecz jej przynależności do bliżej nieokreślonej grupy, gdzie kryterium mogły stanowić powiązania rodowe (?). Zbiorowość ta swoją niezależność manifestowała w taki właśnie sposób - chowając swoich członków w „situlach" lub też tymi naczyniami ich pośmiertnie obdarowując. Ludzie ci zamieszkiwali nie wszystkie wielkopolskie osiedla wielbarskie, z tego też względu „situle” występują tylko na niektórych cmentarzyskach i osadach. Być może w ramach wymiany małżeńskiej ród ten „rozprzestrzeniał się” na kolejne osiedla, a jego członkowie trafiali po śmierci na lokalne cmentarzyska. Aby potwierdzić tę hipotezę, należałoby odkryć i zbadać nekropole prawdopodobnie powiązane z osadami, na których odkryto „situle”. Gdyby rzeczywiście natrafiono na „,itule” w grobach, uzyskalibyśmy potwierdzenie takiego ujęcia. $\mathrm{W}$ takim przypadku przedstawianą mapę znalezisk situl z Wielkopolski (por. mapa 1) należałoby opatrzyć kolejnymi „bliźniaczymi” punktami uzupełniającymi: znane już osady powiązano by z cmentarzyskami i vice versa: znane nekropole $\mathrm{z}$ osiedlami, jak to miało miejsce $\mathrm{w}$ odniesieniu do zespołu z Kowalewka. W chwili obecnej jednak działania takie pozostają jedynie w sferze projektów.

Potwierdzeniem postawionej wyżej hipotezy (w skali mikro) byłaby sytuacja odnotowana właśnie na nekropoli w Kowalewku nr 12, gdzie zarejestrowano koncentrację grobów stanowiących centrum - obszar wyjściowy grupy, a kolejne oddalone pochówki mogłyby wskazywać rozprzestrzenianie się jej członków w ramach wymiany małżeńskiej (?) w obrębie społeczności użytkującej ten obiekt - niekoniecznie pochodzących ze znanej osady w Kowalewku nr 3. Problematycznie jednak w tym świetle rysuje się brak grobów kobiecych w wyżej zaprezentowanym przeglądzie znalezisk wielkopolskich. Wydaje się natomiast, że wysoki odsetek grobów kryjących nieokreślone antropologicznie szczątki ludzkie może mieć kluczowe znaczenie, gdyż tam właśnie mogą znajdować się pochówki kobiece. 
Sytuacje o analogicznej specyfice zostały już zaobserwowane na nekropolach z epoki brązu oraz wczesnego średniowiecza, gdzie stwierdzono, iż odmienności w potraktowaniu zwłok, ich ułożenie w grobie oraz wyposażenie (!) świadczą o zróżnicowaniu rodowym (Rysiewska 1994, s. 51, 52; 1996, s. 96-116) lub etnicznym, czego z kolei dowodzą badania cmentarzysk grupy masłomęckiej, na których odkrywano groby Sarmatek (Kokowski 2007, s. 123-124), oraz kultury bogaczewskiej z zespołami, które formą i wyposażeniem nawiązywały do kultury wielbarskiej (Karczewska, Karczewski 2007, s. 633 i n.).

\section{WNIOSKI}

Rekapitulując powyższe rozważania, można pozytywnie odpowiedzieć na pytanie postawione $\mathrm{w}$ tytule. Zaobserwowano bowiem fenomen, którego wyjaśnienie w obecnej chwili jest niemożliwe. Jednak dzięki analizie materiałów wielkopolskich stało się możliwe tworzenie prawdopodobnych interpretacji odnoszących się do roli „situl” w obrzędowości pogrzebowej ludności wielbarskiej w Wielkopolsce. Należy podkreślić, że przedstawione wyżej hipotezy wymagają weryfikacji w dalszych badaniach terenowych oraz przede wszystkim poprzez analizy w zakresie antropologii kulturowej, etnologii i socjologii. Co niezwykle istotne, badania te muszą objąć cały obszar zasiedlenia ludności kultury wielbarskiej w okresie funkcjonowania „situl”, a więc Pomorze Gdańskie, Pomorze Zachodnie, Powiśle oraz prawobrzeżne Mazowsze i część Mazur. W ujęciu chronologicznym będzie to wczesny okres wpływów rzymskich aż po początek późnego okresu wpływów rzymskich. Jedynie wtedy będzie możliwe stwierdzenie, czy sytuacja dotycząca „situl” zarejestrowana w Wielkopolsce stanowi ewenement na tle pozostałych rejonów zasiedlenia tej ludności, czy też obserwacje poczynione w Wielkopolsce powtórzą się także na innych obszarach.

Niniejszy przyczynek ma jedynie za zadanie poruszyć sieć zagadnień związanych z obecnością ,situl” w inwentarzach ludności wielbarskiej, bez stawiania niepodważalnych stwierdzeń - jest próbą postawienia hipotez. $Z$ tego też względu zagadnienie jest silnie ograniczone przestrzennie, jedynie do Wielkopolski. Rozpoczęta w ten sposób dyskusja powinna jednak w przyszłości, dzięki dalszym badaniom i studiom, przynieść odpowiedź na temat rzeczywistej roli „situl” w obrzędowości pogrzebowej ludności kultury wielbarskiej.

\section{BIBLIOGRAFIA}

Alfawicka S.

1970 Ceramika malowana okresu halsztackiego w Polsce. Wrocław-Warszaw-Kraków: Zakład Narodowy im. Ossolińskich. 
Biedermann $\mathrm{H}$.

2001 Leksykon symboli. Warszawa: Muza S.A.

Bugaj E.

1999 Motywy figuralne na ceramice germańskiego kręgu kulturowego. Poznań: Wydawnictwo Naukowe Uniwersytetu im. Adama Mickiewicza w Poznaniu.

Ciesielski Ł.

2011 Zagospodarowanie przestrzeni cmentarzysk w świetle badań nad stosunkami społecznymi w kulturze przeworskiej. W: W. Dzieduszycki, J. Wrzesiński (red.), Kim jesteś człowieku? Funeralia Lednickie Spotkania 13 (s. 59-68). Poznań: Stowarzyszenie Naukowe Archeologów Polskich.

Dernoga M.

2000a Sprawozdanie $\mathrm{z}$ badań wykopaliskowych na osadzie $\mathrm{z}$ okresu wpływów rzymskich w Tarnowie Pałuckim, stanowisko 13 (gm. Wągrowiec, woj. wielkopolskie). Czwarty sezon badań. W: A.M. Wyrwa (red.), Studia i materiaty do dziejów Pałuk. Tom III. Środowisko naturalne i osadnictwo $w$ tekieńskim kompleksie osadniczym (s. 207-232). Poznań: Wydawnictwo Poznańskie.

Dernoga M.

2000b Osada kultury wielbarskiej z okresu wpływów rzymskich w Siedleczku, stanowisko 4 (gm. Wągrowiec, woj. wielkopolskie). W: A.M. Wyrwa (red.), Studia i materiaty do dziejów Pałuk, t. 3, Środowisko naturalne i osadnictwo w tekieńskim kompleksie osadniczym (s. 184-205). Poznań: Wydawnictwo Poznańskie.

Gałęzowska A.

2004 Osady kultur pomorskiej, przeworskiej i wielbarskiej w Stroszkach w powiecie wrzesińskim. Fontes Archaeologici Posnanienses, 40, s. 281-453.

Karczewska M., Karczewski M.

2007 „Obcy”w grupie. Relacje międzykulturowe na przykładzie pochówków o cechach „,wielbarskich” z cmentarzysk kultury bogaczewskiej. W: M. Fudziński, H. Paner (red.), Nowe materiaty i interpretacje. Stan dyskusji na temat kultury wielbarskiej (s. 627-642). Gdańsk: Muzeum Archeologiczne.

Kokowski A.

2007 Goci. Od Skandzy do Campi Gothorum. Trio Warszawa, Warszawa.

Machajewski H.

2003 Starożytni hutnicy z Pojezierza Gnieźnieńskiego. Wielkopolski Biuletyn Konserwatorski, 2, s. 226-238.

Machajewski H., Sikorski A.

1981 Cmentarzysko ludności kultury wielbarskiej w Lutomiu, gm. Sieraków, woj. Poznań. Fontes Archaeologici Posnanienses, 32, s. 13-24.

Michałowski A., Piasecka K., Piasecki A., Pogodziński P., Żychliński D.

[w druku] Wstępne wyniki ratowniczych badań archeologicznych na osadzie kultury wielbarskiej w Wagowie, pow. poznański, woj. wielkopolskie, stan. 1 i 13.

Przewoźna K.

1955 Osada i cmentarzysko z okresu rzymskiego w Słopanowie, pow. Szamotuły. Fontes Archaeologici Posnanienses, 5, s. 60-139.

Rysiewska T.

1994 Struktury krewniacze i związki międzypopulacyjne w Polsce wczesnośredniowiecznej. Próba wnioskowania na podstawie wybranych cmentarzysk Sandomierszczyzny. Archeologia Polski, 39(1-2), s. 185-190. 
Rysiewska T.

1996 Struktura rodowa w społecznościach pradziejowych. Cmentarzyska z epoki brazu $i$ wczesnej epoki żelaza w poludniowej Polsce. Wrocław: Wydawnictwo Leopoldinum Fundacji dla Uniwersytetu Wrocławskiego.

Skorupka T.

2001 Kowalewko 12. Cmentarzysko birytualne ludności kultury wielbarskiej (od połowy I w. n.e. do początku III w. n.e.). W: M. Chłodnicki (red.), Archeologiczne badania ratownicze wzdhiz trasy gazociagu tranzytowego (t. 2, Wielkopolska, cz. 3). Poznań: Wydawnictwo Poznańskie.

Skorupka T., Strzyżewski C.

2006 Cmentarzysko ludności kultury wielbarskiej w Imilnie, stan. 33, woj. wielkopolskie. Fontes Archaeologici Posnanienses, 42, s. 97-124.

Szamałek K.

2009 Procesy integracji kulturowej $w$ młodszej epoce brazu i poczatkach epoki żelaza na Pojezierzu Wielkopolskim. Poznań: Instytut Archeologii i Etnologii Polskiej Akademii Nauk.

Umbreit C.

1976 Das Gotische Gräberfeld von Brätz Kr. Meseritz. Bonner Hefte zur Vorgeschichte, 11, s. 43-54.

Wołągiewicz R.

1993 Ceramika kultury wielbarskiej między Battykiem a Morzem Czarnym. Szczecin: Muzeum Narodowe.

Woźny J.

2000 Symbolika przestrzeni miejsc grzebalnych $w$ czasach ciałopalenia zwłok na ziemiach Żychliński D.

1999 Osada z późnego okresu wpływów rzymskich w Kowalewku, gm. Oborniki, woj. poznańskie, stanowisko 3. Folia Praehistorica Posnaniensia, 9, s. 173-218.

Żychliński D.

2014 Obrzadek pogrzebowy kultury przeworskiej i wielbarskiej w Wielkopolsce. GnieznoZielona Góra: Wydawnictwo Fundacji Archeologicznej.

\section{THE PHENOMENON OF "SITULAS"? - THE ROLE OF POTTERY VESSELS DETERMINED AS “SITULAS” IN THE WIELBARK CULTURE BURIAL RITE IN WIELKOPOLSKA (GREATER POLAND, POLAND)}

\section{Su m mary}

Discoveries of so called situlas in Wielkopolska (also referred to as Greater Poland) appear to be extremely rare. They have been recorded only at seven sites within the area: three cemeteries and four settlements, with a total number of eighteen vessels of the type, eleven of which were unquestionable. The number of vessels collected from necropolises was respectively eleven and seven, while from the settlements seven and five. Map 1 illustrates the spatial distribution of the 
sites, however, apart from the fact that the cemeteries "gravitate" westwards, and the settlements eastwards, there are no clear rules concerning the pattern. An interesting attempt to define the role of so called situlas in funeral rites observed within Wielbark communities would be to interpret this unique form of a vessel as an urn meant for an exceptional member of a society. Unfortunately, no common features have been observed in the graves with such vessels. Neither did they have special construction, nor typical set of grave goods. Also analyses of bone material revealed significant age distribution.

It seems that archaeological facts presented herein may indirectly indicate that a buried person represented an "alien" - a member of an unspecified group formed on the basis of ancestral connections (?). This community would have manifested its independence by burying its members in the situlas or providing the dead with such vessels as grave goods. As these people did not inhabited all the Wielbark settlements in Wielkopolska, therefore the vessels have occurred only within certain cemeteries and settlements. Particular members of the family might have "spread" to other settlements as a result of a marriage exchange, and were buried in local cemeteries.

Analogous situations have been already observed within necropolises dating to the Bronze and Iron Ages, as well as to the early Middle Ages, where differences in treatment of the dead, such as their position in a grave and goods they have been equipped with, might be interpreted as an evidence of ancestral or ethnic differentiation.

It should be emphasised that the hypotheses presented herein require further research, both fieldworks and analyses concerning cultural anthropology, ethnology and sociology. These studies should be applied to the entire area inhabited by the Wielbark communities in the period when the situlas were in use. 